\title{
A randomized, placebo-controlled trial of complement inhibition in ischemia-reperfusion injury after lung transplantation in human beings
}

\author{
S. Keshavjee, $M D^{\mathrm{a}}$ \\ R. D. Davis, $M D^{b}$ \\ M. R. Zamora, $\mathrm{MD}^{\mathrm{c}}$ \\ M. de Perrot, MD \\ G. A. Patterson, $M D^{d}$
}

From the University of Toronto, Toronto, Ontario, Canada, ${ }^{a}$ Duke University, Durham, $\mathrm{NC}^{\mathrm{b}}$ the University of Colorado, Denver, Colo, ${ }^{\mathrm{c}}$ and Washington University, St Louis, Mo. ${ }^{\mathrm{d}}$

T Cell Sciences Inc provided study drug, placebo, and assistance with data collection and management, Needham, Mass.

Received for publication Jan 4, 2004; revisions received May 9, 2004; accepted for publication June 1, 2004.

Address for reprints: S. Keshavjee, MD, Director, Toronto Lung Transplant Program, Toronto General Hospital, 200 Elizabeth Street, EN 10-224, Toronto, Ontario M5G 2C4, Canada (E-mail: shaf. keshavjee@uhn.on.ca)

J Thorac Cardiovasc Surg 2005;129:423-8 $0022-5223 / \$ 30.00$

Copyright (C) 2005 by The American Association for Thoracic Surgery

doi:10.1016/j.jtcvs.2004.06.048
Objective: Complement activation has been shown to play a significant role in ischemia-reperfusion injury after lung transplantation. TP-10 (soluble complement receptor 1 inhibitor) inhibits the activation of complement by inactivating $\mathrm{C} 3 \mathrm{a}$ and C5a convertases. This was a clinical trial of TP-10 to reduce ischemia-reperfusion injury in lung transplantation.

Methods: In a randomized, double-blinded, multicenter, placebo-controlled trial, 59 patients from four lung transplant programs received TP-10 $(10 \mathrm{mg} / \mathrm{kg}, \mathrm{n}=28)$ or placebo $(\mathrm{n}=31)$ before reperfusion. This dose achieved $90 \%$ complement inhibition for 24 hours, and activity had returned toward normal by 72 hours.

Results: At 24 hours, 14 of 28 patients in the TP-10 group (50\%) were extubated, whereas only 6 of 31 patients in the placebo group $(19 \%)$ were $(P=.01)$. The total times on the ventilator and in the intensive care unit both tended to be shorter in the TP-10 group, but these differences did not achieve statistical significance. Among patients requiring cardiopulmonary bypass $(n=5$ in placebo group and $n=7$ in TP-10 group), the mean duration of mechanical ventilation was reduced by 11 days in the TP-10 group $(10.6 \pm 5.0$ days vs $21.5 \pm 5.9$ days in placebo group, $P=.2)$. Operative deaths, incidences of infection and rejection, and length of hospital stay were not significantly different between the two groups.

Conclusions: Short-term complement inhibition with TP-10 led to early extubation in a significantly higher proportion of lung transplant recipients. The effect of TP-10 was greater among patients undergoing cardiopulmonary bypass, with a large reduction in ventilator days. Complement inhibition thus significantly decreases the duration of mechanical ventilation and could be useful in improving the outcome of lung transplant recipients.

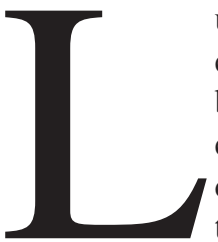

ung transplantation has become a standard therapy for patients with end-stage lung disease. More than 15,000 lung transplantations have been performed worldwide, and approximately 1500 are performed every year. ${ }^{1}$ Despite the recent expansion both in the number of centers performing lung transplantation and in the number of patients undergoing transplantation, ischemia-reperfusion (IR) injury remains an important problem after lung transplantation. ${ }^{2,3}$ It occurs in as many as $10 \%$ to $20 \%$ of patients, despite the recent introduction of low-potassium dextran solution (Perfadex; Vitrolife, Goteborg, Sweden) to preserve the lungs, and still represents the prime cause of early morbidity and mortality. ${ }^{4}$ In addition, there is 
TABLE 1. Patient characteristics

\begin{tabular}{lccc}
\hline & $\begin{array}{c}\text { TP-10 } \\
\text { (n= 28) }\end{array}$ & $\begin{array}{c}\text { Placebo } \\
(\mathbf{n}=\mathbf{3 1})\end{array}$ & $\boldsymbol{P}$ value \\
\hline Age (y) & & & \\
Mean \pm SEM & $53.4 \pm 10.5$ & $51.8 \pm 7.8$ & .5 \\
18-60 (No.) & 24 & 28 & .6 \\
$\quad$ 60 (No.) & 4 & 3 & \\
Sex (No.) & & & .6 \\
$\quad$ Male & 19 & 19 & \\
Female & 9 & 12 & \\
Lung transplantation (No.) & & & .7 \\
$\quad$ Single & 16 & 16 & \\
$\quad$ Bilateral & 12 & 15 & \\
Pathology (No.) & & & \\
$\quad$ Emphysema & 19 & 20 & \\
Pulmonary fibrosis & 3 & 6 & \\
Pulmonary hypertension & 4 & 4 & \\
$\quad$ Other & 2 & 1 & \\
\hline
\end{tabular}

some evidence to suggest a relationship between IR injury and both acute rejection and chronic graft dysfunction. ${ }^{5,6}$

Prediction of early lung dysfunction has been difficult because of the complexity of the interactions between the donor lung and the recipient. ${ }^{7}$ A large number of interventions have been performed experimentally to limit the release of inflammatory mediators and to improve the quality of the lung. ${ }^{8}$ However, relatively few treatment options have been translated into clinical practice. ${ }^{9}$

Complement is a collective term used to describe a group of plasma and cell membrane proteins that play a key role in the cell defense process. ${ }^{10}$ Animal experiments have shown that activation of the complement system may lead to cellular injury through direct and indirect mechanisms during lung ischemia and reperfusion. ${ }^{11,12}$ Complement receptor 1 is a natural complement antagonist that has been cloned and the transmembrane portion removed to obtain a soluble form (sCR1). sCR1 can suppress both the classic and the alternative pathways of complement activation by inhibiting $\mathrm{C} 3$ and C5 convertases. We and others have shown in a swine single-lung transplantation model that the administration of sCR1 to the recipient before reperfusion significantly reduces lung edema and improves lung function. ${ }^{13,14}$ In response to these results, we undertook a multicenter trial to evaluate whether complement inhibition with SCR1 (TP10) would lead to reduced IR injury and improved outcomes in human lung transplantation.

\section{Materials and Methods}

We performed a randomized, double blind, placebo-controlled trial at four North American lung transplant centers. These centers were the University of Toronto, Duke University, the University of Colorado, and Washington University. The study drug and placebo were provided by $\mathrm{T}$ Cell Sciences Inc. Patients with end-stage pulmonary disease undergoing lung transplantation surgery were enrolled in the trial. Patients with cystic fibrosis or with infectious conditions such as bronchiectasis were excluded from the study because of the theoretic possibility that complement inhibition might impair the ability to fight infection. All patients received standard care, including immunosuppressive therapies, antirejection therapies, and anti-infection therapies, as determined by the principal investigator at each institution. Pharmacists in each center randomly assigned patients at the time of transplantation and provided drug or placebo in a blinded fashion. Lung preservation methods were similar between the centers, with a bolus of $500 \mu \mathrm{g}$ prostaglandin $\mathrm{E}_{1}$ followed by an anterograde flush of Euro-Collins solution injected through the pulmonary artery and hypothermic preservation during transport.

A total of 59 patients enrolled in the study were randomly assigned to either the TP-10 group $(n=28)$ or the placebo group $(\mathrm{n}=31)$. One patient was excluded because of incomplete dose administration. One patient received placebo instead of the drug and was perforce transferred to the placebo group. There was no significant difference between groups in age, sex, type of transplantation, and underlying lung disease (Table 1). The drug was administered at a dose of $10 \mathrm{mg} / \mathrm{kg}$ through a period of 30 minutes before reperfusion of the first allograft. This dose has been shown to achieve $>90 \%$ complement inhibition for 24 to 48 hours, with a return to normal activity by 72 hours. ${ }^{15}$

The primary end point was the time to extubation. We considered the duration of mechanical ventilation to be a clinically important end point for a phase III study, because it reflects the severity of IR injury, intensive care unit (ICU) morbidity, and resource use. Secondary end points were as follows: $\mathrm{PaO}_{2} /$ inspired oxygen fraction ratio, ICU and hospital stays, and survival. Chest radiographs performed on postoperative day (POD) 1, POD 2, and POD 3 were blindly reviewed by a radiologist, and scores of 0 to 5 were attributed to the upper, middle, and lower zones of each transplanted lung. A score of 0 defined a clear chest radiograph, and a score of 5 was given when the entire zone was consolidated. The total score (0-15 for each lung) was multiplied by 2 for patients with single-lung transplants. The incidences of acute rejection and infection were also recorded. Safety parameters and pharmacokinetics of the drug were also analyzed. All surviving patients were prospectively followed up for 6 months after the transplantation.

\section{Assessment of Complement Activity}

The inhibitory effect of TP-10 on the complement system was determined by the Mayer hemolysis method to measure complement activity $\left(\mathrm{CH}_{50}\right)$ and by the level of $\mathrm{C} 3 \mathrm{a}$ in the blood, as described previously elsewhere. ${ }^{13}$ To carry out these assays, blood was collected before administration of the drug and at 12, 24, 48, and 72 hours after reperfusion, as well as on the POD 5.

\section{Statistical Analysis}

Data collection and management was carried out by T Cell Sciences. All data analysis was supervised by the principal investigators (S.K., R.D.D., M.R.Z., G.A.P.). Results are expressed as mean \pm SEM. Categoric variables were analyzed by Fisher exact test or $\chi^{2}$ test, and continuous variables were analyzed by Student $t$ test. Repeated-measures analysis of variance and planned com- 


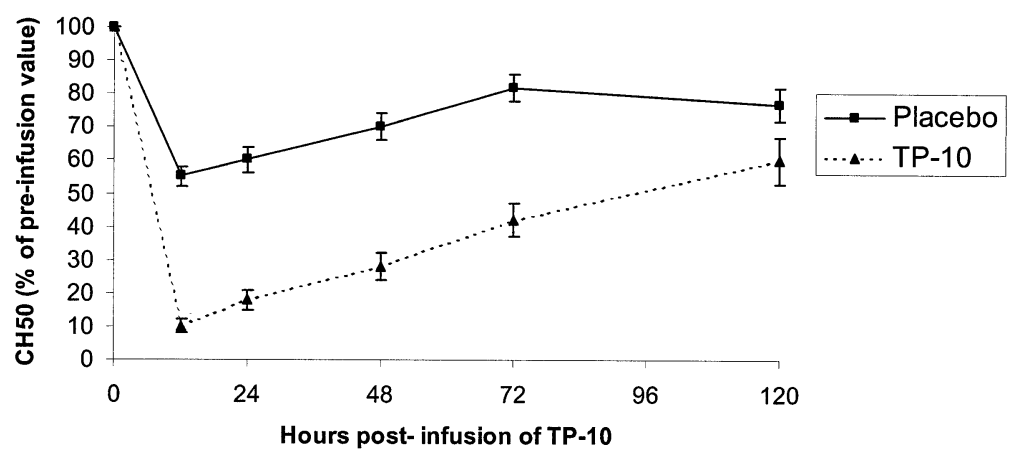

Figure 1. Complement inhibition in lung transplantation. Effect of TP-10 on $\mathrm{CH}_{50}$ values after reperfusion.

parison was used to measure the effects of TP-10 on C3a levels and $\mathrm{CH}_{50}$ values after reperfusion.

\section{Results}

\section{Complement Activity}

Complement activity was in fact reduced during the initial 24 to 72 hours after reperfusion in both the placebo and TP-10 groups. However, complement activity was reduced by a maximum of $45 \%$ in the control group, whereas it was reduced by as much as $90 \%$ in the TP-10 group (Figure 1). The level of $\mathrm{C} 3 \mathrm{a}$ decreased during the initial 72 hours after reperfusion in the TP-10 group, whereas it increased immediately after reperfusion in the placebo group (Figure 2). After 5 days, the complement activity and the level of $\mathrm{C} 3 \mathrm{a}$ were back to similar values in both the placebo and TP-10 groups (Figures 1 and 2).

\section{Mortality}

A total of 5 patients died in the early postoperative period ( $<28$ days), $2(7.1 \%)$ in the TP-10 group and $3(9.7 \%)$ in the control group $(P=.1)$. In addition, 7 patients died between 1 and 6 months after the operation, $5(19.2 \%)$ in the TP-10 group and $2(7.1 \%)$ in the control group $(P=.2$; Table 2$)$.

\section{Postoperative Results}

Although the $\mathrm{PaO}_{2}$ /inspired oxygen fraction ratio on arrival at the ICU was not significantly different between the two groups, TP-10 led to a significant increase in the rate of early extubation. At 24 hours, 14 of 28 patients in the TP-10 group $(50 \%)$ were extubated, whereas only 6 of 31 patients in the control group $(19 \%)$ were extubated $(P=.01)$. The total duration of mechanical ventilation tended to be shorter in the TP-10 group, but this finding did not achieve statistical significance $(8.2 \pm 2.9$ days in TP-10 group vs $13.1 \pm$ 3.2 days in control group, $P=.3$ ). If patients who died during ventilation were excluded, however, the total time on the ventilator was indeed significantly shorter in the TP-10 group (6.4 \pm 2.3 days in TP-10 group vs $16.3 \pm 3.7$ in control group, $P=.03$ ). There were no significant differences in ICU and hospital stays between the two groups
(Table 3). There were no significant difference in the chest radiograph score between the two groups on POD 1 (10 \pm 7 in TP-10 group vs $9 \pm 7$ in placebo group, $P=.6$ ), POD 2 (11 \pm 7 in TP-10 group vs $12 \pm 7$ in placebo group, $P=$ $.6)$, and POD 3 (11 \pm 6 in TP-10 group vs $12 \pm 8$ in placebo group, $P=.5$ ).

\section{Cardiopulmonary Bypass}

A total of 12 patients required cardiopulmonary bypass (CPB). There were 7 patients in the TP-10 group (25\%) with a mean $\mathrm{CPB}$ time of $3.3 \pm 1.2$ hours and 5 patients in the control group (16\%) with a mean CPB time of $4.2 \pm 0.4$ hours. The mean duration of mechanical ventilation was reduced by 11 days in the TP-10 group (10.6 \pm 5.0 days in TP-10 group vs $21.5 \pm 5.9$ days in control group, $P=.2$ ), and the ICU stay was reduced by 6 days $(16.4 \pm 5.4$ days in TP-10 group vs $22.4 \pm 6.4$ days in control group, $P=.5$ ).

\section{Episodes of Infection and Rejection}

In the TP-10 and control groups, 41 and 64 infectious episodes, respectively, occurred within 6 months after surgery ( $P$ not significant). Among them, 18 in the TP-10 group and 29 in the control group occurred in the early postoperative period ( $<28$ days, $P$ not significant). Twentytwo patients in each group had at least one episode of rejection. The total numbers of rejection episodes were 34 in the TP-10 group and 32 in the control group ( $P$ not significant).

\section{Discussion}

IR injury is a complex process that involves the release of several mediators, leading to tissue injury and to the infiltration of inflammatory cells such as lymphocytes and neutrophils. ${ }^{16}$ The infiltrating inflammatory cells can perpetuate the initial inflammatory reaction and induce further injuries. Recent studies have recognized the predominant role of mediators such as cytokines, adhesion molecules, plateletactivating factor (PAF), leukotrienes, P-selectin, and endothelin. ${ }^{8}$ The complement system is an important mediator of 


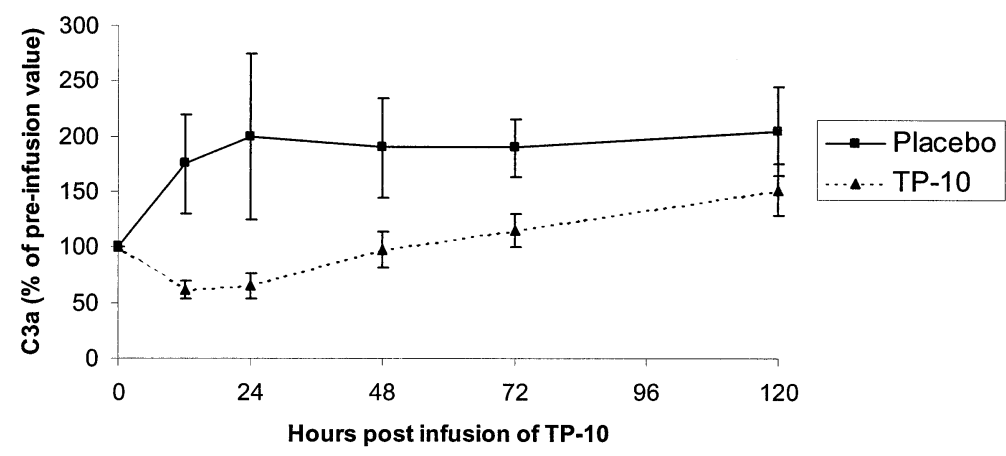

Figure 2. Complement inhibition in lung transplantation. Effect of TP-10 on C3a levels after reperfusion.

TABLE 2. Causes of mortality in control and TP-10 groups

\begin{tabular}{|c|c|c|c|}
\hline Patients & POD & Cause of death & Ventilated \\
\hline \multicolumn{4}{|c|}{ Control group } \\
\hline 1 & 9 & Primary graft failure & Yes \\
\hline 2 & 14 & Sepsis/pneumonia & Yes \\
\hline 3 & 28 & $\begin{array}{l}\text { Multiple-system organ } \\
\text { failure/sepsis }\end{array}$ & Yes \\
\hline 4 & 73 & Perforated colon/sepsis & No \\
\hline 5 & 176 & Cytomegalovirus & No \\
\hline \multicolumn{4}{|l|}{ TP-10 group } \\
\hline 1 & 6 & Primary graft failure & Yes \\
\hline 2 & 11 & Myocardial infarct & Yes \\
\hline 3 & 57 & Duodenal ulcer/sepsis & No \\
\hline 4 & 71 & Respiratory failure & Yes \\
\hline 5 & 93 & $\begin{array}{l}\text { Respiratory syncytial virus } \\
\text { pneumonia }\end{array}$ & No \\
\hline 6 & 97 & Sepsis & No \\
\hline 7 & 166 & Diverticulitis/sepsis & No \\
\hline
\end{tabular}

the inflammatory process that is rapidly activated in the course of IR injury. ${ }^{11,12}$ Furthermore, it is considered to be the first link between the innate and acquired immune systems. ${ }^{17}$

Activation of the complement cascade results in the release of several biologically active products, such as $\mathrm{C} 3 \mathrm{a}$ and C5a, also called anaphylatoxins, and the formation of the membrane attack complex $\mathrm{C} 5 \mathrm{~b}-\mathrm{C} 9 .{ }^{10} \mathrm{C} 5 \mathrm{~b}-\mathrm{C} 9$ is a macromolecular complex capable of forming a channel through the plasma membrane, which directly causes target cell lysis. C5b-C9 can also upregulate adhesion molecules, stimulate the release of PAF and cytokines, and promote the procoagulant properties of endothelium. ${ }^{18} \mathrm{C} 5 \mathrm{~b}-\mathrm{C} 9$ has been reported to be the main mediator of complement-induced injury in a mouse model of warm ischemia of the kidney. ${ }^{18}$

Complement factor C5a is a potent neutrophil and lymphocyte chemoattractant that is rapidly released after reperfusion. ${ }^{19}$ In animal models of heart ischemia, specific neutralization of $\mathrm{C} 5 \mathrm{a}$ or $\mathrm{C} 5 \mathrm{a}$ receptor at the time of reperfusion has been shown to reduce infarct size and to decrease
TABLE 3. Postoperative results

\begin{tabular}{|c|c|c|c|}
\hline & $\begin{array}{c}\text { TP-10 } \\
(\mathrm{n}=28)\end{array}$ & $\begin{array}{l}\text { Placebo } \\
(\mathrm{n}=31)\end{array}$ & $P$ value \\
\hline Ischemic time $(\mathrm{h})^{*}$ & $4.4 \pm 0.3$ & $4.0 \pm 0.3$ & .4 \\
\hline $\begin{array}{l}\mathrm{PaO}_{2} \text { /inspired oxygen } \\
\text { fraction }(\mathrm{mm} \mathrm{Hg}) \dagger\end{array}$ & $345 \pm 34$ & $378 \pm 38$ & .5 \\
\hline Early extubation (No.) & 14 & 6 & .01 \\
\hline Intubation (d) & $8.2 \pm 2.9$ & $13.1 \pm 3.2$ & .3 \\
\hline $\begin{array}{l}\text { Intubation among } \\
\text { survivors (d) } \ddagger\end{array}$ & $6.4 \pm 2.3$ & $16.3 \pm 3.7$ & .03 \\
\hline ICU stay (d) & $12.5 \pm 3.1$ & $14.8 \pm 4.4$ & .7 \\
\hline Hospital stay $(d)$ & $33.4 \pm 5.4$ & $30.8 \pm 4.8$ & .7 \\
\hline
\end{tabular}

Data represent mean \pm SEM except as noted.

*Ischemic times from the second lung were used for bilateral transplants. $†$ On arrival to ICU.

$\ddagger$ Excluding patients who died during ventilation ( $n=3$ in each group).

neutrophil activation and accumulation. ${ }^{19-22}$ The effect of C5a and C3a inhibition has not been directly demonstrated in lung transplantation. However, the intrabronchial instillation of C3a, C5a, or both in guinea pigs has been shown to induce acute lung injury, and specific C5a inhibition has been shown to reduce acute lung injury induced by immunoglobulin $G$ immune complexes or by intestinal IR injury. ${ }^{23-25}$

Inhibition of the complement system with sCR1 prevents the release of anaphylatoxins and the formation of the complex C5b-C9. ${ }^{26}$ The administration of sCR1 before reperfusion has been shown to reduce IR injury experimentally in a number of organs, such as the lung, heart, liver, and intestine. ${ }^{13,14,27-29}$ To the best of our knowledge, this study is the first report of administration of sCR1 in clinical lung transplantation. The study was a multicenter, randomized, double-blind, placebo-controlled trial that included a total of 59 patients undergoing lung transplantation. In it, short-term complement inhibition at the time of reperfusion led to early extubation in a significantly higher proportion of patients; that is, the number of patients extubated within the 
first 24 hours after transplantation in the TP-10 group was more than double that in the control group.

Although patients' ventilation protocols were not standardized among the centers, the finding that $50 \%$ of the patients in the TP10 group were extubated within 24 hours, whereas only $19 \%$ in the placebo group were, is a striking difference that is unlikely to have been observed by chance alone. In addition, the median time to extubation was similar between centers, and three of the centers tended to have a shorter time to extubation in the TP-10 group.

The effect of complement inhibition was greater in the subgroup of patients undergoing CPB. We observed a reduction of 11 days in the mean duration of mechanical ventilation and of 6 days in the mean ICU stay relative to the control group. Although the difference was not statistically significant because of the small number of patients, the clinical significance of this drug effect is potentially important. Patients requiring CPB have a double-hit injury, IR and $\mathrm{CPB}$. Thus the benefit of complement inhibition in this subset of patients is likely to be much greater.

Two other double-blind, placebo-controlled, randomized trials have been completed in lung transplantation in an attempt to reduce the degree of IR injury, and neither showed striking differences. Wittwer and colleagues ${ }^{30}$ reported the effect of a PAF antagonist in 24 patients undergoing bilateral lung transplantation and found a tendency toward better oxygenation during the initial 24 hours after reperfusion in the two groups of patients treated with PAF antagonists than in the control group. In a double-blind, placebo-controlled, randomized trial studying the effect of prophylactic inhaled nitric oxide on IR injury in more than 80 patients, ${ }^{31}$ no differences in immediate oxygenation, time to extubation, stay in the ICU, and 30-day mortality were observed between the two groups. That study demonstrated that despite the apparently valuable clinical role of nitric oxide in the treatment of established IR injury, inhaled nitric oxide does not appear to prevent the development of IR injury.

The redundancy of the innate immune system makes it difficult to reduce IR injury by inhibiting only one pathway, such as the complement system. Thus several authors have recently reported on the effects of combined inhibitors of the innate immune system. Schmid and coworkers ${ }^{32}$ have shown that dual strategies, such as associating sCR1 with sialyl Lewis X, a potent ligand for selectin adhesion molecules inhibiting neutrophil migration, can have a cumulative beneficial effect. The combination of SCR1 and sialyl Lewis $\mathrm{X}$ improved lung function and reduced neutrophil migration as well as lipid peroxidation relative to SCR1 alone. ${ }^{33}$ Modulation of more than one pathway of IR injury seems to be a promising strategy that remains to be validated in future clinical trials.
In summary, we have shown that TP-10 decreases the magnitude of IR injury after lung transplantation in human beings. A significantly greater number of patients treated with the drug were extubated within 24 hours after transplantation. Importantly, this study underscores the importance of multicenter trials to answer important questions in lung transplantation. The strength of this study lies in the fact that it represents a randomized, double-blind, placebocontrolled, clinical trial in IR injury after lung transplantation. Even with the involvement of four large lung transplant centers, however, this study was still relatively underpowered to be able to statistically demonstrate important differences. With the development of novel agents for the modulation of lung preservation and IR injury, larger multicenter cooperative trials will be required to critically appraise the value of their translation into clinical application.

We acknowledge Una S. Ryan and James L. Levin from T Cell Sciences Inc for their assistance in carrying out this study.

\section{References}

1. Trulock EP, Edwards LB, Taylor DO, Boucek MM, Mohacsi PJ, Keck $\mathrm{BM}$, et al. The registry of the international society for heart and lung transplantation: twentieth official adult lung and heart-lung transplant report-2003. J Heart Lung Transplant. 2003;22:625-35.

2. King RC, Binns OA, Rodriguez F, Kanithanon RC, Daniel TM, Spotnitz WD, et al. Reperfusion injury significantly impacts clinical outcome after pulmonary transplantation. Ann Thorac Surg. 2000;69: 1681-5.

3. Christie JD, Bavaria JE, Palevsky HI, Litzky L, Blumenthal NP, Kaiser LR, et al. Primary graft failure following lung transplantation. Chest. 1998;114:51-60.

4. Fischer S, Matte-Martyn A, de Perrot M, Waddell TK, Sekine Y, Hutcheon $\mathrm{M}$, et al. Low-potassium dextran preservation solution improves lung function after human lung transplantation. J Thorac Cardiovasc Surg. 2001;121:594-6.

5. Waddell TK, Gorczynski RM, DeCampos KN, Patterson GA, Slutsky AS. Major histocompatibility complex expression and lung ischemiareperfusion in rats. Ann Thorac Surg. 1996;62:866-72.

6. Fiser SM, Tribble CG, Long SM, Kaza AK, Kern JA, Jones DR, Robbins MK, Kron IL. Ischemia-reperfusion injury after lung transplantation increases risk of late bronchiolitis obliterans syndrome. Ann Thorac Surg. 2002;73:1041-7.

7. Sommers KE, Griffith BP, Hardesty RL, Keenan RJ. Early lung allograft function in twin recipients from the same donor: risk factor analysis. Ann Thorac Surg. 1996;62:784-90.

8. de Perrot M, Liu M, Waddell TK, Keshavjee S. Ischemia-reperfusion induced lung injury. State-of-the-art. Am J Respir Crit Care Med. 2003;167:490-511.

9. McRae KM. Pulmonary transplantation. Curr Opin Anaesthesiol. 2000;13:53-9.

10. Frank MM. Complement in the pathophysiology of human disease. N Engl J Med. 1987;316:1525-30.

11. Naka Y, Marsh HC, Scesney SM, Oz MC, Pinsky DJ. Complement activation as a cause for primary graft failure in an isogeneic rat model of hypothermic lung preservation and transplantation. Transplantation. 1997;64:1248-55.

12. Bishop MJ, Giclas PC, Guidotti SM, Su ML, Chi EY. Complement activation is a secondary rather than a causative factor in rabbit pulmonary artery ischemia/reperfusion injury. Am Rev Respir Dis. 1991;143:386-90.

13. Pierre AF, Xavier AM, Liu M, Cassivi SD, Lindsay TF, Marsh HC, et al. Effect of complement inhibition with soluble complement recep- 
tor 1 on pig allotransplant lung function. Transplantation. 1998;66: 723-32.

14. Schmid RA, Zollinger A, Singer T, Hillinger S, Leon-Wyss JR, Schob $\mathrm{OM}$, et al. Effect of soluble complement receptor type 1 on reperfusion edema and neutrophil migration after lung allotransplantation in swine. J Thorac Cardiovasc Surg. 1998;116:90-7.

15. Zimmerman JL, Dellinger RP, Straube RC, Levin JL. Phase I trial of the recombinant soluble complement receptor 1 in acute lung injury and acute respiratory distress syndrome. Crit Care Med. 2000;28: 3149-54.

16. de Perrot M, Young K, Imai Y, Liu M, Waddell TK, Fischer S, et al. Recipient $\mathrm{T}$ cells mediate reperfusion injury after lung transplantation in the rat. J Immunol. 2003;171:4995-5002.

17. Kohl J. Anaphylatoxins and infectious and non-infectious inflammatory diseases. Mol Immunol. 2001;38:175-87.

18. Zhou W, Farrar CA, Abe K, Pratt JR, Marsh JE, Wang Y, et al. Predominant role for C5b-9 in renal ischemia/reperfusion injury. J Clin Invest. 2000;105:1363-71.

19. Ivey CL, Williams FM, Collins PD, Jose PJ, Williams TJ. Neutrophil chemoattractants generated in two phases during reperfusion of ischemic myocardium in the rabbit. Evidence for a role for C5a and interleukin-8. J Clin Invest. 1995;95:2720-8.

20. Tanhehco EJ, Lee H, Lucchesi BR. Sublytic complement attack reduces infarct size in rabbit isolated hearts: evidence for C5a-mediated cardioprotection. Immunopharmacology. 2000;49:391-9.

21. Riley RD, Sato H, Zhao ZQ, Thourani VH, Jordan JE, Fernandez AX, et al. Recombinant human complement C5a receptor antagonist reduces infarct size after surgical revascularization. J Thorac Cardiovasc Surg. 2000;120:350-8.

22. Amsterdam EA, Stahl GL, Pan HL, Rendig SV, Fletcher MP, Longhurst JC. Limitation of reperfusion injury by a monoclonal antibody to C5a during myocardial infarction in pigs. Am J Physiol. 1995;268(1 Pt 2):H448-57.

23. Stimler NP, Hugli TE, Bloor CM. Pulmonary injury induced by C3a and C5a anaphylatoxins. Am J Pathol. 1980;100:327-38.

24. Mulligan MS, Schmid E, Beck-Schimmer B, Till GO, Friedl HP,
Brauer RB, et al. Requirement and role of C5a in acute lung inflammatory injury in rats. J Clin Invest. 1996;98:503-12.

25. Heller T, Hennecke M, Baumann U, Gessner JE, zu Vilsendorf AM, Baensch M, et al. Selection of a C5a receptor antagonist from phage libraries attenuating the inflammatory response in immune complex disease and ischemia/reperfusion injury. J Immunol. 1999;163: 985-94.

26. Rioux P. TP-10 (AVANT Immunotherapeutics). Curr Opin Investig Drugs. 2001;2:364-71.

27. Shandelya SM, Kuppusamy P, Herskowitz A, Weisfeldt ML, Zweier JL. Soluble complement receptor type 1 inhibits the complement pathway and prevents contractile failure in the postischemic heart. Evidence that complement activation is required for neutrophilmediated reperfusion injury. Circulation. 1993;88:2812-26.

28. Lehmann TG, Koeppel TA, Kirschfink M, Gebhard MM, Herfarth C, Otto $\mathrm{G}$ et al. Complement inhibition by soluble complement receptor type 1 improves microcirculation after rat liver transplantation. Transplantation. 1998;66:717-22.

29. Eror AT, Stojadinovic A, Starnes BW, Makrides SC, Tsokos GC, Shea-Donohue T. Antiinflammatory effects of soluble complement receptor type 1 promote rapid recovery of ischemia/reperfusion injury in rat small intestine. Clin Immunol. 1999;90:266-75.

30. Wittwer T, Grote M, Oppelt P, Franke U, Schaefers HJ, Wahlers T. Impact of PAF antagonist BN 52021 (Ginkolide B) on post-ischemic graft function in clinical lung transplantation. $J$ Heart Lung Transplant. 2001;20:358-63.

31. Meade M, Granton JT, Matte-Martyn A, McRae K, Weaver B, Cripps $\mathrm{PM}$, et al. A randomized trial of inhaled nitric oxide to prevent ischemia-reperfusion injury after lung transplantation. Am J Respir Crit Care Med. 2003;167:1483-9.

32. Schmid RA, Hillinger S, Hamacher J, Stammberger U. TP20 is superior to TP10 in reducing ischemia/reperfusion injury in rat lung grafts. Transplant Proc. 2001;33:948-9.

33. Stammberger U, Hamacher J, Hillinger S, Schmid RA. sCR1sLe ameliorates ischemia/reperfusion injury in experimental lung transplantation. J Thorac Cardiovasc Surg. 2000;120:1078-84. 